\title{
PENGARUH KREDIBILITAS SELEBRITI TERHADAP MINAT BELI PRODUK TEH SIAP MINUM PADA DEWASA AWAL
}

\author{
Nabilah Umami ${ }^{1}$, Rita Markus Idulfilastri ${ }^{2}$, Meike Kurniawati ${ }^{3}$ \\ ${ }^{1}$ Program Sarjana Psikologi, Universitas Tarumanagara Jakarta \\ Email: nabilah.705170267@stu.untar.ac.id \\ ${ }^{2}$ Fakultas Psikologi, Universitas Tarumanagara Jakarta \\ Email: ritamarkus@fpsi.untar.ac.id \\ ${ }^{3}$ Fakultas Psikologi, Universitas Tarumanagara Jakarta \\ Email:meikek@fpsi.untar.ac.id
}

Masuk : 03-08-2021, revisi: 03-08-2021, diterima untuk diterbitkan : 29-10-2021

\begin{abstract}
Celebrities, especially those who appointed to promote certain products must have high credibility in order to effectively influence consumer purchase intentions and purchase decisions. Celebrity's credibility is the ability of celebrities to convince consumers and create effective promotions to increase consumer purchases of certain products. Purchase intention is a measurable psychological drive in an individual to determine the possibility of someone buying a product/service. This study aims to examine the effect of celebrity's credibility on purchase intention for ready-to-drink tea products in early adulthood. This study involves 436 participants consisting of 10 men and 426 women. This research uses quantitative research methods with sampling techniques that are non probability sampling. The measuring instruments used are The Source Credibility Scale (Ohanian, 1990) adapted by Stephanie et. al (2013), Purchase Intention Scale by Osei-frimpong (2019). The results of data analysis used a simple linear regression technique whose regression equation was Celebrity's Credibility $=3,416+0,623$ Purchase Intention, $R^{2}=38,7 \%$ with $p=0,000<0,05$. These results indicate that celebrity's credibility affects purchase intention with a determination $\left(R^{2}\right) 38$, 7. In other words, the celebrity's credibility influences purchase intention in ready-to-drink tea products for early adulthood.
\end{abstract}

Keywords: Celebrity credibility, purchase intention, ready to drink tea, young adult.

\begin{abstract}
ABSTRAK
Selebriti, terutama yang ditunjuk untuk mempromosikan produk tertentu harus memiliki kredibilitas yang tinggi agar dapat dengan efektif memengaruhi minat beli konsumen. Kredibilitas selebriti merupakan kemampuan selebriti untuk meyakinkan konsumen dan membuat promosi yang dilakukan efektif untuk meningkatkan pembelian konsumen terhadap produk tertentu. Minat beli adalah dorongan psikologis pada individu yang dapat diukur untuk mengetahui kemungkinan seseorang untuk membeli suatu produk atau jasa. Penelitian ini bertujuan untuk menguji pengaruh kredibilitas selebriti terhadap minat beli produk teh siap minum pada dewasa awal. Penelitian ini melibatkan 436 partisipan yang terdiri dari 10 laki-laki dan 426 perempuan.Penelitian ini menggunakan metode penelitian kuantitatif dengan teknik sampling yaitu non probability sampling. Alat ukur yang digunakan adalah The Source Credibility Scale (Ohanian, 1990) yang diadaptasi oleh Stephanie et.al (2013) dan Purchase Intention Scale oleh Osei-frimpong (2019). Hasil analisis data menggunakan teknik regresi linear sederhana yang persamaan regresinya yaitu Kredibilitas Selebriti $=3,416+0,623$ Minat Beli, $\mathrm{R}^{2}=38,7 \%$ dengan $\mathrm{p}=0,000<0,05$. Hasil ini menunjukkan bahwa kredibilitas selebriti mempengaruhi minat beli dengan determinasi $\left(\mathrm{R}^{2}\right)$ sebesar 38,7. Dengan kata lain, kredibilitas selebriti mempengaruhi minat beli produk teh siap minum pada dewasa awal.
\end{abstract}

Kata Kunci: Kredibilitas selebriti, minat beli, teh siap minum, dewasa awal.

\section{PENDAHULUAN}

\section{Latar Belakang}

Selebriti, menurut Kamus Bahasa Inggris Cambridge memiliki arti yaitu orang yang terkenal, terutama dalam bidang hiburan (Cambridge English Dictionary, 2020). Penelitian selama beberapa dekade secara konsisten menemukan bahwa selebriti dianggap sebagai role model dan konsultan yang memengaruhi pengambilan keputusan seseorang (Brown \& Basil, 2010). Terkadang, sebagian orang menganggap selebriti tersebut merupakan teman dengan banyaknya interaksi yang dilakukan oleh selebriti dengan pengikutnya di sosial media dan membuat seseorang merasa harus 
membeli barang-barang yang dipakai, ataupun yang dipromosikan oleh selebriti tersebut untuk menunjukkan loyalitas ataupun memperkuat hubungan seseorang dengan selebriti yang diidolakan (Russell et al., 2004; Sakib et al., 2020).

Berdasarkan data-data tersebut, tidak heran jika para pengusaha sejak bertahun-tahun lalu menggunakan jasa selebriti dengan menjadikan selebriti tersebut endorser, ambassador, ataupun spokeperson untuk mempromosikan produk tertentu. Pengusaha berharap dengan memasangkan produk dengan selebriti tertentu, perasaan positif yang orang-orang punya terhadap selebriti tersebut dapat ditransfer ke sebuah produk yang membuat orang-orang memiliki minat beli yang tinggi terhadap produk tersebut (Halonen-Knight \& Hurmerinta, 2010).

Minat beli sendiri dipengaruhi oleh berbagai macam faktor seperti faktor internal dan eksternal. Faktor internal dari minat beli sendiri yaitu motivasi, persepsi, sikap, dan keyakinan (Ticoalu, 2015), sedangkan faktor eksternalnya adalah kemasan produk dan promosi (Shafiq et al., 2011).

Penelitian-penelitian terdahulu menemukan bahwa keefektifan promosi oleh selebriti untuk meningkatkan minat beli konsumen juga dipengaruhi oleh beberapa hal. Hal pertama adalah kecocokan selebriti dengan merek tersebut. Jika image yang dimiliki oleh selebriti tersebut cocok dengan konsep merek dan produk yang ditawarkan, hal itu dapat meningkatkan keinginan membeli konsumen (Thwaites et al., 2012). Contohnya adalah Adidas menjadikan David Beckham sebagai salah satu selebriti yang mempromosikan merek tersebut karena David Beckham memiliki latar belakang yaitu pemain sepakbola dan merupakan orang yang aktif berolahraga sehingga cocok dengan Adidas yang merupakan merek di bidang olahraga.

Penelitian juga menemukan bahwa loyalitas selebriti pada merek tersebut memengaruhi minat beli konsumen. Selebriti yang mempromosikan hanya satu merek dikatakan lebih meningkatkan minat beli konsumen dibandingkan dengan selebriti yang mempromosikan beberapa merek sekaligus (Ilicic \& Webster, 2011; Rice et al., 2012). Penelitian lainnya juga mengatakan bahwa hubungan antara selebriti dan konsumen serta kepribadian konsumen sendiri memengaruhi minat beli yang dimiliki konsumen (Chung \& Cho, 2017; Escalas \& Bettman, 2017; Tran et al., 2019).

Terakhir dan paling banyak diteliti, yaitu kredibilitas selebriti berpengaruh pada minat beli konsumen. Kredibilitas selebriti sendiri memiliki tiga dimensi yang dapat diukur, yaitu attractiveness, trustworthiness, dan expertise (Amos et al., 2008). Meskipun begitu, ada penelitian yang mengganti dimensi expertise dengan familiarity dengan alasan dimensi tersebut dirasa lebih berpengaruh pada produk dan daerah yang diteliti (Osei-Frimpong et al., 2019). Hasilnya menunjukkan bahwa jika kredibilitas selebriti tinggi, maka minat membeli konsumen terhadap produk yang dipromosikan juga akan meningkat (Amos et al., 2008; Osei-Frimpong et al., 2019). Hal ini disebabkan karena konsumen merasa yakin bahwa informasi yang disampaikan oleh selebriti dengan kredibilitas tinggi adalah suatu hal yang valid atau benar yang dapat memengaruhi sikap dan cara pandang konsumen pada barang yang dipromosikan (Tormala et al., 2006).

Penelitian terdahulu mengenai pengaruh selebriti, banyak dihubungkan dengan minat beli. (Daneshvary \& Schwer, 2000; Osei-Frimpong et al., 2019; Tran et al., 2019). Dalam penelitian ini, peneliti berupaya untuk menguji pengaruh selebriti terhadap minat beli. Perbedaan antara penelitian ini dengan penelitian sebelumnya, yaitu penelitian sebelumnya memilih produk seperti fashion dan kosmetik (Chen et al., 2013; Pradhan et al., 2016; Rice et al., 2012). Pada penelitian ini, peneliti memilih sektor produk teh siap minum karena menurut penelitian sebelumnya, produk dengan low involvement akan lebih efektif dengan metode promosi seperti dengan selebriti karena 
konsumen tidak akan terlalu banyak mencari informasi mengenai produk tersebut dan konsumen tidak sadar dengan efek tingginya minat beli yang dihasilkan oleh promosi melalui selebriti.

Menurut data statistik pada tahun 2018 pengikut selebriti di sosial media didominasi oleh kelompok usia remaja dan dewasa awal. 72\% dari populasi usia 16-24 tahun dan 64\% dari populasi usia 25-34 tahun menjadi pengikut selebriti di sosial media (Clement, 2018). Hal ini juga menjadi pertimbangan peneliti dalam memilih produk teh siap minum untuk diteliti karena menurut survey, $56,2 \%$ orang mengaku sering mengkonsumsi teh siap minum yang biasanya berada pada rentang usia 15-35 tahun (Snapchart, 2017).

Di dunia, terdapat lebih dari 100 merek teh siap minum yang dikonsumsi di pasaran seperti Lipton, Arizona, Nestea, dan lain-lain (Beverage Marketing Corporation, 2019; Zenith Global Report, 2016). Di Indonesia sendiri terdapat kurang lebih 12 merek yang memproduksi teh siap minum yang masing-masing juga menghasilkan beberapa produk dengan varian rasa yang berbeda (Lingga, 2018). Hal ini membuktikan bahwa teh siap minum merupakan sektor yang tepat untuk diteliti karena tingginya minat pasar dan persaingan antar merek terutama di Indonesia.

\section{Rumusan Masalah}

Rumusan masalah dalam penelitian ini adalah apakah kredibilitas selebriti memengaruhi minat beli produk teh siap minum pada dewasa awal?

\section{Minat Beli}

Minat beli didefinisikan sebagai rencana keputusan atau kecenderungan niat seseorang untuk membeli suatu produk atau merek tertentu (Belch \& Belch, 2003; Peter \& Olson, 2012; Wu et al. 2012). Menurut Schiffman dan Kanuk (2009) minat beli didefinisikan sebagai sebuah dorongan psikologis pada individu yang dapat diukur untuk mengetahui kemungkinan seseorang untuk membeli suatu produk atau jasa.

Minat beli dipengaruhi oleh faktor internal, antara lain (Lucas dan Britt, 2012): (a) perhatian: adanya perhatian yang besar dari konsumen terhadap produk yang akan dibeli; (b) ketertarikan: adanya fokus perhatian dan rasa senang atas produk yang akan dibeli; (c) keinginan: adanya dorongan untuk memiliki produk yang akan dibeli; (d) keyakinan: adanya kepercayaan diri atas kegunaan, kualitas, dan keuntungan dari produk yang akan dibeli. Minat beli juga dipengaruhi oleh faktor eksternal, yaitu perceived usefulness (PU), harga, dan electronic word-of mouth (eWOM) (Liew \& Falahat, 2017).

Dapat disimpulkan bahwa minat beli merupakan keinginan seseorang untuk membeli suatu produk yang dapat mengukur kemungkinan sesungguhnya apakah seseorang akan membeli produk tersebut

\section{Kredibilitas Selebriti}

Selebriti merupakan seseorang yang terkenal dan mendapat rekognisi publik karena perhatian yang diberikan kepada orang tersebut oleh media massa. Selebriti sendiri mendapat status tersebut karena berbagai macam hal, yaitu memiliki kekayaan, dekat dengan selebriti lain, merupakan atlet, politisi, atau seseorang yang berkecimpung di dunia hiburan (Collins English Dictionary, 2020). Menurut Ziek (2016) selebriti adalah individu-individu yang dipilih oleh publik. Selebriti juga didefinisikan sebagai individu yang telah mencapai tingkat ketenaran yang membuat individu tersebut terkenal dalam masyarakat (Mark Young \& Pinsky, 2006). 
Kredibilitas selebriti sendiri merupakan kemampuan selebriti untuk meyakinkan konsumen dan membuat promosi yang dilakukan efektif untuk meningkatkan pembelian konsumen terhadap produk tertentu (Osei-Frimpong et al., 2019). Menurut Ohanian (1990) kredibilitas selebriti didefinisikan sebagai sejauh mana selebriti dapat dipercaya. Menurut Belch \& Belch (2003) kredibilitas selebriti merupakan sejauh mana konsumen melihat selebriti memiliki pengetahuan, keterampilan, dan pengalaman yang relevan dan mempercayai selebriti dalam memberikan informasi secara obyektif.

Menurut Ohanian (1990) terdapat tiga aspek dari kredibilitas selebriti, yaitu (a) Attractiveness: penampilan fisik dari seorang selebriti; (b) Expertise: seberapa besar pengetahuan, kemampuan, dan pengalaman yang dimiliki selebriti tertentu untuk mempromosikan suatu produk' (c) Trustworthiness: tingkat kepercayaan yang dimiliki selebriti untuk menyampaikan informasi yang diinginkan.

\section{METODE PENELITIAN}

Penelitian ini menggunakan metode penelitian kuantitatif dengan teknik sampling yaitu non probability sampling. Jenis sampling yang digunakan adalah convenience sampling. Subyek penelitian ini memiliki kriteria yaitu berusia 18-40 tahun, pernah membeli produk teh siap minum dengan metode promosi menggunakan selebriti paling tidak sekali, dan mengetahui selebriti yang mempromosikan produk teh siap minum tersebut. Sampel penelitian ini berjumlah 436 orang partisipan. Pengambilan data dilakukan secara daring menggunakan Google Form yang berisi data partisipan, informed consent, dan alat ukur kredibilitas selebriti serta minat beli.

\section{HASIL DAN PEMBAHASAN}

Gambaran partisipan penelitian ini berdasarkan usia yaitu terdiri dari kelompok usia 18-23 tahun yang berjumlah 370 orang (84,9\%), kelompok usia 24-29 tahun yang berjumlah 53 orang $(12,2 \%)$, kelompok usia 30-35 tahun yang berjumlah 11 orang (2,5\%), dan kelompok usia 36-40 tahun berjumlah 2 orang $(0,5 \%)$. Selanjutnya, gambaran partisipan berdasarkan jenis kelamin yaitu terdapat 426 perempuan $(97,7 \%)$ dan 10 laki-laki $(2,3 \%)$. Kemudian, gambaran partisipan berdasarkan uang saku atau pendapatan yaitu kelompok uang saku/pendapatan $<500.000$ sebanyak 187 orang (42,9\%), kelompok uang saku atau pendapatan 500.001-2.500.000 sebanyak 178 orang (40,8\%), kelompok uang saku/pendapatan 2.500.001-3.500.000 sebanyak 34 orang (7,8\%), kelompok uang saku atau pendapatan 3.500.001-5.000.000 sebanyak 24 orang (5,5\%), dan kelompok uang saku/pendapatan $>5.000 .000$ sebanyak 13 orang $(3 \%)$.

Sebelum melakukan uji hipotesis, peneliti terlebih dahulu melakukan uji asumsi klasik yaitu uji normalitas, uji linearitas, dan uji heteroskedastisitas sebagai syarat uji regresi linear sederhana. Uji asumsi klasik menggunakan One Sample Kolmogorov-Smirnov didapatkan output berupa signifikansi sebesar 0,327>0,05 yang berarti data terdistribusi normal. Selanjutnya, uji linearitas dilakukan dan didapatkan output berupa signifikansi dari Deviation from Linearity sebesar $0,334>0,05$ yang berarti terdapat hubungan linear antar variabel. Terakhir, uji heteroskedastisitas dilakukan menggunakan scatter plot dan karena tidak adanya pola yang terbentuk, dapat dikatakan bahwa data tidak memiliki gejala heteroskedastisitas.

Uji hipotesis dilakukan dengan regresi linear sederhana dan didapatkan hasil berupa signifikansi $0,000<0,05$ dengan persamaan regresi $\mathrm{Y}=3,416+0,623 \mathrm{X}$. Data tersebut menunjukkan bahwa kredibilitas selebriti memiliki hubungan yang positif dengan minat beli sehingga jika kredibilitas naik, maka minat beli juga akan meningkat. Berdasarkan data-data tersebut, dapat dikatakan 
bahwa hipotesis penelitian diterima yaitu kredibilitas selebriti memengaruhi minat beli produk teh siap minum pada dewasa awal. Data lebih lengkap dapat dilihat pada tabel 1.

\section{Tabel 1}

Hasil Uji Regresi

\begin{tabular}{lccccc}
\hline \multicolumn{1}{c}{ Variabel } & B & Std. Error & Beta & t & (Sig.) \\
\hline (Constant) & 3,416 & 1,273 & & 2,683 & 0,008 \\
Kredibilitas selebriti & 0,361 & 0,022 & 0,623 & 16,604 & 0,000 \\
\hline
\end{tabular}

a. Dependent variable: Minat Beli

Selanjutnya peneliti melihat hasil dari koefisien determinasi untuk mengetahui besar kontribusi kredibilitas selebriti terhadap minat beli. Hasil menunjukkan bahwa didapatkan adjusted R square sebesar 0,387 yang dapat diartikan bahwa kredibilitas selebriti berkontribusi terhadap minat beli sebesar 38,7\%. Data lebih rinci dapat dilihat di tabel 2.

\section{Tabel 2}

Model Summary

\begin{tabular}{|c|c|c|c|}
\hline Variabel & $\mathbf{R}$ & R Square & Adjusted R Square \\
\hline $\begin{array}{l}\text { Kredibilitas selebriti terhadap } \\
\text { minat beli }\end{array}$ & 0,623 & 0,388 & 0,387 \\
\hline
\end{tabular}

Berdasarkan analisis regresi dimensi expertise terhadap minat beli didapatkan nilai signifikansi sebesar 0,000, nilai $\mathrm{R}=0,466$, dan nilai Adjusted $R$ Square $=0,216$, sehingga dapat dikatakan bahwa dimensi expertise berpengaruh langsung terhadap minat beli sebesar $21,6 \%$. Analisis regresi dimensi trustworthiness terhadap minat beli didapatkan nilai signifikansi sebesar 0,000 , nilai $\mathrm{R}=0,531$, dan nilai Adjusted $R$ Square $=0,281$, sehingga dapat dikatakan bahwa dimensi trustworthiness berpengaruh langsung terhadap minat beli sebesar $28,1 \%$. Analisis regresi dimensi attractiveness terhadap minat beli didapatkan nilai signifikansi sebesar 0,000 , nilai $\mathrm{R}=0,608$, dan nilai Adjusted $R$ Square $=0,368$, sehingga dapat dikatakan bahwa dimensi attractiveness berpengaruh langsung terhadap minat beli sebesar 36,8\%. Berdasarkan data tersebut dapat disimpulkan bahwa dimensi attractiveness mempunyai pengaruh langsung paling besar terhadap minat beli.

Tabel 3

Uji Regresi Dimensi Kredibilitas Selebriti Terhadap Minat Beli

\begin{tabular}{lccc}
\hline \multicolumn{1}{c}{ Dimensi } & Variabel Dependen & $\begin{array}{c}\text { Adjusted } \boldsymbol{R} \\
\text { Square }\end{array}$ & (Sig.) \\
\hline Expertise & Minat Beli & 0,216 & 0,000 \\
Trustworthiness & Minat Beli & 0,281 & 0,000 \\
Attractiveness & Minat Beli & 0,368 & 0,000 \\
\hline
\end{tabular}

Berdasarkan hasil tersebut, dapat dikatakan bahwa kredibilitas selebriti memiliki pengaruh yang signifikan terhadap minat beli produk teh siap minum pada dewasa awal. Hal ini sejalan dengan penelitian Osei-Frimpong et al. (2019) dan memperkuat pernyataan Spry et al. (2011) yang mengatakan bahwa kredibilitas selebriti merupakan salah satu faktor yang memengaruhi minat beli.

Jika konsumen merasa seorang selebriti mempunyai kredibilitas tinggi, maka konsumen akan mempercayai perkataan atau informasi yang selebriti berikan adalah valid atau benar. Saat pikiran muncul sebagai respon dari informasi yang dianggap valid karena disampaikan oleh selebriti dengan kredibilitas tinggi, konsumen akan percaya diri dengan pikiran tersebut. Kepercayaan diri 
pada pikiran konsumen mengenai barang yang dipromosikan akhirnya memunculkan sikap konsumen untuk berminat terhadap barang tersebut (Tormala et al., 2006).

\section{KESIMPULAN DAN SARAN}

Berdasarkan hasil olah data pada pembahasan sebelumnya, dapat disimpulkan bahwa kredibilitas selebriti memiliki pengaruh yang signifikan terhadap minat beli produk teh siap minum pada dewasa awal dengan kontribusi sebesar 38,7\%. Dimensi kredibilitas selebriti yang paling besar kontribusinya terhadap minat beli adalah attractiveness.

Saran peneliti untuk bidang psikologi konsumen yang menjadi fokus dari penelitian ini adalah agar meneliti lebih dalam mengenai perilaku konsumen terutama dalam topik yang berhubungan dengan selebriti karena meskipun sudah ada beberapa penelitian mengenai topik tersebut, sangat jarang yang membahas dari sisi psikologi.

Peneliti juga menyarankan agar penelitian selanjutnya dapat meningkatkan jumlah partisipan terutama untuk laki-laki agar terdapat keseimbangan jumlah antara laki-laki dan perempuan. Selain itu, peneliti selanjutnya juga dapat menambahkan variabel yang sekiranya memengaruhi kredibilitas selebriti dengan minat beli. Dari hasil penelitian sebelumnya, variabel brand awareness dan brand image dapat dihubungkan dengan kredibilitas selebriti untuk mengetahui pengaruh antar variabel. Penelitian selanjutnya juga dapat meneliti lebih jauh hingga keputusan pembelian dengan penelitian eksperimen dan memerhatikan hal-hal eksternal seperti harga produk, urgensi kebutuhan, dan sebagainya.

Saran praktis yang dapat peneliti berikan untuk perusahaan teh siap minum, yaitu dapat mencari selebriti dengan kredibilitas yang tinggi terutama dalam dimensi attractiveness agar dapat memengaruhi minat beli konsumen secara lebih efektif.

\section{Ucapan Terima Kasih (Acknowledgement)}

Peneliti mengucapkan terima kasih kepada Tuhan Yang Maha Esa (YME), kedua orang tua peneliti, Fakultas Psikologi Universitas Tarumanagara, dan teman-teman yang tidak dapat peneliti sebutkan satu-persatu yang telah membantu peneliti selama proses pembuatan skripsi ini. Terima kasih juga untuk partisipan yang sudah membantu mengisi kuesioner penelitian ini dan membantu proses pengumpulan data.

\section{REFERENSI}

Amos, C., Holmes, G., \& Strutton, D. (2008). Exploring the relationship between celebrity endorser effects and advertising effectiveness: A quantitative synthesis of effect size. International Journal of Advertising, 27(2), 209-234. https://doi.org/10.1080/02650487.2008.11073052

Belch, G. E., \& Belch, M.A.. (2003). Advertising and promotion. In Advanced Social Media Marketing (6th ed.). https://doi.org/10.1007/978-1-4302-4408-0_4

Beverage Marketing Corporation. (2019, Juli 15). 2019 Ready to drink tea: USA industry trends \& market analysis report. Beverage Marketing. https://www.beveragemarketing.com/shop/rtd-tea-in-the-us.aspx

Brown, W. J., \& Basil, M. D. (2010). Parasocial interaction and identification: Social change processes for effective health interventions. Health Communication, 25(6), 601-602. https://doi.org/10.1080/10410236.2010.496830

Cambridge English Dictionary. (2020, September 24). Celebrity. Cambridge English dictionary. https://dictionary.cambridge.org/dictionary/english/celebrity 
Chen, A. C.-H., Chang, R. Y.-H., Besherat, A., \& Baack, D. W. (2013). Who benefits from multiple brand celebrity endorsements? An experimental investigation. Psychology \& Marketing, 30(10), 850-860. https://doi.org/10.1002/mar

Chung, S., \& Cho, H. (2017). Fostering parasocial relationships with celebrities on social media: Implications for celebrity endorsement. Psychology and Marketing, 34(4), 481-495. https://doi.org/10.1002/mar.21001

Clement, J. (2018, Juli 22). Global celebrity social media audience reach by age 2018. Statista. https://www.statista.com/statistics/408414/celebrity-social-media-audience-age/

Collins English Dictionary. (2020). Celebrity definition and meaning. Collins English Dictionary. https://www.collinsdictionary.com/dictionary/english/celebrity

Daneshvary, R., \& Schwer, R. K. (2000). The association endorsement and consumers' intention to purchase. Journal of Consumer Marketing, 17(3), 203-213. https://doi.org/10.1108/07363760010328987

Escalas, J. E., \& Bettman, J. R. (2017). Connecting with celebrities: How consumers appropriate celebrity meanings for a sense of belonging. Journal of Advertising, 46(2), 297-308. https://doi.org/10.1080/00913367.2016.1274925

Halonen-Knight, E., \& Hurmerinta, L. (2010). Who endorses whom? Meanings transfer in celebrity endorsement. Journal of Product and Brand Management, 19(6), 452-460. https://doi.org/10.1108/10610421011085767

Liew, Y. S. \& Falahat, M. (2019). Factors influencing consumers' purchase intention towards online group buying in Malaysia. International Journal of Electronic Marketing and Retailing, 10(1), 60-77, https://doi.org/10.1504/IJEMR.2019.10017363

Lingga, H. (2018, September 3). Teh kemasan: Adu jitu strategi merebut pasar milenial. Warta Ekonomi. https://www.wartaekonomi.co.id/read193631/teh-kemasan-adu-jitu-strategimerebut-pasar-milenial.html

Lucas, D. B., \& Britt, S. H., 2012. Measuring advertising effectiveness. McGraw-Hill.

Young, S. M., \& Pinsky, D. (2006). Narcissism and celebrity. Journal of Research in Personality, 40(5), 463-471. https://doi.org/10.1016/j.jrp.2006.05.005

Ohanian, R. (1990). Construction and validation of a scale to measure celebrity endorsers' perceived expertise, trustworthiness, and attractiveness. Journal of Advertising, 19(3), 3952. https://doi.org/10.1080/00913367.1990.10673191

Osei-Frimpong, K., Donkor, G., \& Owusu-Frimpong, N. (2019). The Impact of Celebrity Endorsement on Consumer Purchase Intention: An Emerging Market Perspective. Journal of Marketing Theory and Practice, 27(1), 103-121. https://doi.org/10.1080/10696679.2018.1534070

Peter, P. J., \& Olson, J. C. (2012). Consumer Behavior Marketing. McGraw-Hill.

Pradhan, D., Duraipandian, I., \& Sethi, D. (2016). Celebrity endorsement: How celebrity-branduser personality congruence affects brand attitude and purchase intention. Journal of Marketing Communications, https://doi.org/10.1080/13527266.2014.914561

456-473.

Rice, D. H., Kelting, K., \& Lutz, R. J. (2012). Multiple endorsers and multiple endorsements: The influence of message repetition, source congruence and involvement on brand attitudes. $\begin{array}{llll}\text { Journal of } & \text { Consumer } & \text { 245ychology, 259. }\end{array}$ https://doi.org/10.1016/j.jcps.2011.06.002

Russell, C. A., Norman, A. T., \& Heckler, S. E. (2004). The consumption of television programming: Development and validation of the connectedness scale. Journal of Consumer Research, 31(1), 150-161. https://doi.org/10.1086/383431

Sakib, M. N., Zolfagharian, M., \& Yazdanparast, A. (2020). Does parasocial interaction with weight loss vloggers affect compliance? The role of vlogger characteristics, consumer 
readiness, and health consciousness. Journal of Retailing and Consumer Services, 52(January 2019), 101733. https://doi.org/10.1016/j.jretconser.2019.01.002

Schiffman, L. G., Kanuk, L. L. (2009). Perilaku konsumen. Indeks Group Gramedia.

Shafiq, R., Raza, I., \& Zia-ur-Rehman, M. (2011). Analysis of the factors affecting customers' purchase intention: The mediating role of perceived value. African Journal of Business Management, 5(26), 10577-10585. https://doi.org/10.5897/ajbm10.1088

Snapcart. (2017, Maret 13). Ready to Drink Tea in Indonesia. Snapcart Global. https://snapcart.global/ready-drink-tea-indonesia/

Spry, A., Pappu, R., \& Cornwell, T. B. (2011). Celebrity endorsement, brand credibility and brand equity. European Journal of Marketing, 45(6). https://doi.org/10.1108/03090561111119958

Stephanie, E., Rumambi, L. J., \& Kunto, Y. S. (2013). Analisa pengaruh Rio Dewanto dan Donita sebagai celebrity endorser terhadap minat beli produk axe anarchy dengan daya tarik iklan dan efek iklan sebagai variabel intervening. Manajemen Pemasaran, 1(2), 1-2.

Thwaites, D., Lowe, B., Monkhouse, L. L., \& Barnes, B. R. (2012). The impact of negative publicity on celebrity ad endorsements. Psychology \& Marketing, 29(9), 663-673. https://doi.org/10.1002/mar

Ticoalu, V. (2015). The Analysis of customer purchase intention of houses using real estate agent in Manado based on psychological factors. Jurnal Berkala Ilmiah Efisiensi, 16(1), 649660. https://doi.org/10.35794/emba.v3i4.11079

Tormala, Z. L., Briñol, P., \& Petty, R. E. (2006). When credibility attacks: The reverse impact of source credibility on persuasion. Journal of Experimental Social Psychology, 42(5), 684691. https://doi.org/10.1016/j.jesp.2005.10.005

Tran, G. A., Yazdanparast, A., \& Strutton, D. (2019). Investigating the marketing impact of consumers' connectedness to celebrity endorsers. Psychology and Marketing, 36(10), 923935. https://doi.org/10.1002/mar.21245

Wu, W. Y., Lu, H. Y., Wu, Y. Y., \& Fu, C. S. (2012). The effects of product scarcity and consumers' need for uniqueness on purchase intention. International Journal of Consumer Studies, 36(3), 263-274. https://doi.org/10.1111/j.1470-6431.2011.01000.x

Zenith Global Report. (2016, Oktober 25). Global RTD tea report- growth markets and technology advances. Zenith Global. https://www.zenithglobal.com/market-insights/reports/globalrtd-tea-report-growth-markets-and-technology-advances

Ziek, P. (2016). Cultivating celebrity through public relations. Celebrity Studies, 7(1), 122-124. https://doi.org/10.1080/19392397.2016.1131015 